\title{
International Comparative Study of Virtual Currency Supervision in Block Chain
}

\author{
Xin Wen \\ School of International Finance and Banking, University of Science and Technology Liaoning, \\ Anshan City, Liaoning Province, 114051, China. \\ crazy_poet@126.com
}

Keywords: Bitcoin; virtual currency; supervision.

\begin{abstract}
In order to explore the virtual currency supervision and compare the differences of it in different countries, taking bitcoin as an example, first of all, the measurements for supervising bitcoin are compared between China and America. In addition, the causes for the difference are further analyzed from social nature, Internet financial mode, and bitcoin industry. Based on this, the countermeasures for China to strengthen bitcoin supervision are put forward. The results showed that the factors for different supervision ideas are various. For the macro level, it includes social system; and for the micro level, it involves consumer's consumption concept. As a result, it is concluded that it is necessary to fully combine with the national conditions and efficiently absorb advanced concept when learning and studying supervision systems with Chinese characteristics.
\end{abstract}

\section{Introduction}

The rapid development of the Internet and other communication systems has promoted the realization of the virtualization and electronization of currency. It is also bound to promote a series of reforms, such as the model of market integration, the mode of operation and the mode of settlement. Bitcoin as a new product, its emergence makes people begin to think about the new form of currency. Combined with Hayek's opinion, whether bitcoin can become a substitute for the succedaneum of legal currency has become the focus of attention [1]. Money laundering, terrorist organization financing tools, illegal transactions and transaction security and so on are gradually displayed around the emergence of the crisis of bitcoin trading. All countries have divergence about whether to supervise bitcoin or how to supervise bitcoin, and even take opposite measures. China, as a market that occupies $90 \%$ bitcoin trading volume, has many different performances with the US which strictly controls the bitcoin transaction in terms of supervision and specific measures. This reflects the huge differences between China and the US in terms of economy, politics and supervision.

In the bitcoin operation activities, the market size of the United States and China is great, the planning of implementation of supervision is also paid attention to all over the world. The comparative study of the differences between the two countries of the supervision system is carried out, to explore the supervision form that caters the characteristics of China. It improves the regulatory policy comprehensively, avoid a series of real crisis brought by bitcoin, and ensure increasingly robust and safe development of China financial markets [2]. At the same time, it will provide regulatory direction for China to issue digital currency, and establish a relatively complete and reasonable management mechanism to reduce market risk and effectively improve the status of Internet finance in China.

Through the different attitudes of China and the US towards monitoring bitcoin, the paper explores the differences between China and the US in the financial development process, and takes the lead to explore the deep-seated economic problems between China and the US from the perspective of bitcoin. This paper analyzes the regulatory system of China and the United States by means of comparative study, and analyzes the differences in the economic structure, supervision mode, establishment of the system and the financial model difference between China and the United States. 
In view of the current situation of China's upcoming research and distribution of digital currency, the rationalization proposal is put forward from the perspective of the research of bitcoin.

\section{Measurements For Bitcoin Supervision}

The official supervision of bitcoin or its development is the main problem that has been retained among countries since the official output of bitcoin in 2009. Each country has made different measures according to its own economic situation and system construction. Some countries, led by the US and China, believed that there are huge risks for bitcoin in transactions on the Internet, terrorist activities and system construction [3]. Therefore, it is necessary for the state to supervise bitcoins. Therefore, it is also supposed to have a general understanding of bitcoin. As shown in table 1 , it is the comparison between bitcoin and Q coin [4].

Table 1. The difference between bitcoin and Q coin

\begin{tabular}{ccc}
\hline & Bitcoin & Q coin \\
\hline Issuer & No & Tencent Inc \\
Scope of use & Global & Tencent Inc series products \\
Scope of payment & Global business & Tencent Inc series products \\
Commodity property & Yes, it has. & It lacks. \\
Can it trade? & Yes, it can. & Yes, it can. \\
Circulation & Two-way circulation & One-way circulation \\
Investment value & It has investment value, but it also has great risk & Unlimited \\
Price control & Dtermined by the market & Controlled by Tencent Inc \\
\hline
\end{tabular}

\subsection{China's Regulatory Measures}

China's supervision of bitcoin has been divided into two stages so far. The first stage, the government, in order to reduce the bitcoin speculation heat, deny its currency properties and prohibit banks and other payment institutions involved in the business. But each big application platform and online transactions take the basic website management measures, which has not substantively constrained transactions related to bitcoin. At this stage, the national financial institutions launched a bitcoin transaction stage, but no regulatory online trading platform promotes that China quickly becomes the bitcoin trading country. It attracts more investors to take advantage of loopholes in the regulatory network for arbitrage transactions, making bitcoin market in China extremely unstable [5]. The second stage, as the bitcoin market carries out the "financing currency" business, bitcoin transactions have leverage risk. This business rapidly expands the bitcoin transaction risk, so the Central Bank begins to attach importance to the supervision of the trading platform. And through on-site inspection, it examines the platform qualification and it is prohibited to carry out "financing currency" business, which solve the leverage risk fundamentally. At the same time, according to the practice of other countries, it begins to charge the special currency transaction fee to reduce the arbitrage attracted by the low operating cost.

Studying the series system of Chinese government supervising bitcoin, China refused to identify bitcoin as currency. In addition, China didn't allow financial unit to operate related activities, on-site inspection and other practices, which effectively curbed irrational investors' attempts to gain high profits by manipulating bitcoins. But China takes bitcoin as a virtual goods with the fuzzy boundaries also troubles the orderly regulation. China has been in a passive ban in bitcoin regulatory issues, yet no active analysis of bitcoin risk sources and effects, so as to formulate specific and targeted regulation. It also makes bitcoin online trading in China still in the "shadow" areas of management, and there are still many illegal arbitrage activities that are not shown in the existing regulatory environment.

\subsection{US Regulatory Measures}

The development of Internet finance has become increasingly mature, so bitcoin is generated. The risk it may bring is first of all analyzed in detail, and the four major risks that should focus on are summed up. In a wide range of applications, businesses must give the sending in accordance with the provisions of the high cash report; in the taxes, according to mining, exchange, utilization of multiple 
links, the tax is paid [6]. And, it requires to master the operating activities of the platform, enhance the publicity system and ensure that the legitimate rights and interests of the investors are not damaged.

Comparing the two countries bitcoin regulatory measures, it can be seen that, first of all, China and the United States do not recognize bitcoin as the currency, and both denied the possibility of it as the legal currency. Secondly, two countries are aware of the risk impact of bitcoin on financial market, and begin to conduct regulatory actions. But in the specific implementation process, China did not actively seek out special bitcoin regulatory system or method. On the contrary, only by prohibiting banking institutions, it blocked its influence on the traditional financial. However, it opens "a window" for bitcoin in the development of Internet finance. In the transactions, it does not requires the tax, platform qualification summary, convenient online operation and so on features [7]. All of these attract a large number of investors for Chinese bitcoin market. However, lack of reason and supervision of trading result in the market risk increased. In view of the US, for the risks brought by bitcoin, we need to conduct regulatory actions rapidly. In the process of formulating regulatory system, we should set up systematic solutions and conduct supervision activities effectively from assessment research to multi sector joint law enforcement.

Chinese bitcoin market is greatly active out of the regulatory red line, which adds a lot of uncertainties to the China Internet financial market. It is a great test for the development of the Internet finance. While the United States bitcoin market tends to be more reasonable in trade investment in the orderly regulation. What's more, it requires to make use of advanced technology of bitcoin in other areas, so as to realize the financial system with technology sharing and the burden of risk.

\section{Analysis of Factors for the Difference of Bitcoin Between China and the United States}

\subsection{Social Nature Difference}

China's social system: China implements the basic socialist system. For our country's social and economic development process, we have always stressed Chinese characteristics and must go out of a way of development suitable for Chinese characteristics. For this reason, the development mode of our country is centered around the development of social economy, supplemented by reform and development, and actively promotes the overall development of productive forces. And during the implementation of reform, we should further improve the economic system and political system. After the third Plenary Session of the 11th CPC Central Committee, China has gradually implemented the progressive reform method, which has obviously improved the people's living standard and changed the social structure [8].

The United States social system: The United States practise capitalist system, and pursue free market and free enterprise in the economy aspect. At the personal level, the premise is personal interest and wealth, and the ultimate goal is to satisfy personal spirit and value orientation. A completely different social system will inevitably result in different results between China and the United States in dealing with reform. For a capitalist country like the US, it is a development mode that emphasizes liberalization and marketization. It makes full use of market competition mechanism, and the law of value spontaneously adjusts the economic operation. Therefore, when the United States received a change, it requires more flexibility, and it will more real-time change or re-establish system according to the changes; Chinese mode adds more government macro-control of the market, and in the face of change, it will occur the situation of system establishment delay [9]. However, it is precisely because of the government intervention policy of China's mode that the economic development can be stable and avoid the possible chaos that the United States is too free to regulate.

\subsection{Internet Financial Model}

China's Internet financial model: For Chinese social economy, the development is not mature. The protection based on the government in the financial sector shows strong monopoly. The innovation ability is poor, the imbalance in the service concept and the allocation of resources fails to deal with diversified market demand of consumers, and most capitals flow continuously to the banking sector. For the field of Internet, its development is fast, and its competitiveness is very strong. Therefore, due 
to the emergence of Internet finance, Internet company has been expanding into the financial market to further expand its market share, so as to achieve innovation and development.

American Internet financial model: For the US social economy, the development is relatively mature. The competitiveness of technology and financial industry is huge, resource matching is more standardized, and the profit margins in various fields are relatively stable. As a result, for the Internet financial model, it generally can be divided into two categories [10]. One is from the traditional financial enterprises to actively seek innovation, to change the pay state in the previous line, and to make a reasonable use of Internet technology to enhance the level of service. The other is based on the financial impact of the Internet environment, the newly formed without entity only appears in the Internet financial platform, and creates its unique business network. Therefore, for the US Internet finance industry, in the process of rapid development, it can also promote the rapid transformation and development of the traditional financial industry, thereby highlighting the professionalism and rigour in the field, as well as achieving the purpose of being specific and precise.

\subsection{Bitcoin Industry Difference}

Today, it has a distinct difference for China and the US bitcoin industries. There is a certain relationship between bitcoin business and mining in our country, but bitcoin related settlement, network consumption, game projects are rare. On the other hand, the majority of entrepreneur's bitcoin in the United States takes the main storage and application as the core, creating a number of high technology start-ups that attach great importance to bitcoin utilization and block chain.

The concentrate mining and trading attracted more speculative investors for China bitcoin market. The government, in order to maintain the stability of the basic financial order, prohibits financial institutions bitcoin trading but not against the use of network transactions. While in the United States, more consumers use bitcoin. They give full play to the use value and technical value of bitcoin and abandon simply speculative profits, for the pursuit of a more long-term investment income. The industry differences and policy differences mutually influence, resulting in that the trading of bitcoin in China is more convenient than that in the United States, China has thus become the world's largest bitcoin mining country. Convenient sale will also bring the risk of speculation, and flexible trading environment will attract speculators and even criminals. The convenience of the Internet and omission of regulatory arbitrage are used for fraud and other illegal acts in the China trading platform, which will also be a serious blow to our country at the stage of development of Internet banking. Therefore, in order to better develop Internet finance, ordered bitcoin regulation is the topic needed to be paid attention to in China.

\section{Measures for the Supervision of Bitcoin}

Firstly, it is necessary to estimate the risk accurately. The risk of bitcoin is not only the loss of capital, but also the serious consequences of terrorist organizations such as money laundering, hacker malicious attacks, market disorder and so on. Before setting up a correct regulatory strategy, we should first accurately predict the possible risks. The main industry mode of bitcoin market in China is analyzed. According to the direction of consumers, investment willingness and development prospects, we can identify possible risks and formulate effective supervision strategies for specific risks. Referring to the regulation mode in the United States, bitcoin development in the United States is mainly around the bitcoin applications. For instance, block chain technology is used to conduct business or the development of bitcoin second industry. Therefore, the United States will define it as a commodity, which provides the possibility for it being active in the capital market [11]. The United States also regulates the relevant bitcoin futures and other financial products. At the same time, it also encourages the good development of entrepreneurial enterprises. In China, for bitcoin in China, due to various reasons, the market is still in the stage based on speculative arbitrage. We should focus on, in the process of Internet financial transactions in the market, the laundering, bubble risk of using the characteristics of anonymity, center removal and so on [12]. In supervision, we should pay more attention to safety standard, establish the sound trading rules, and make a comprehensive study of transactions involving the third party platform. 
Secondly, it requires to set up a special supervision system. We study the regulatory system of Internet finance in the US. Based on traditional financial regulation, it is mainly related to preventing systemic crisis, ensuring financial consumers and complete information publicity. However, due to the uniqueness of Internet finance, for the regulatory mode and method, the US often weighs in innovation and risk, financial consumer maintenance and market profitability. First of all, we need to make clear the idea of Internet finance. From the domestic analysis of the industry, most researchers point out that the industry is realized under the current financial regulatory policy. There is a certain correlation between the phenomenon and the current financial system. Therefore, Internet finance needs no specific regulation, but it needs to choose the existing regulatory system [13]. According to the experience of global development, it is an important development trend to choose a specific regulatory system that is relatively lax in this industry. Consequently, China must also be clear of the Internet financial concept in the field of supervision, and build a series of regulatory systems and plans to promote the overall development of its industry.

Thirdly, we should make full use of the opportunities of bitcoin and Internet financial development. We will build Internet settlement tools and form a regulatory system. In the future, the networking of global life is an important trend. More and more social networking and financial transactions are coming into the network platform. China must take the opportunity to create the bitcoin design so as to meet the requirements of our country's basic national conditions and the legal and policy requirements. The United States Consumer Financial Protection Center issued the complaint cases of related digital currency for goods and services in 2014 [14]. It made it clear for China bitcoin transaction processing dispute complaint handling department. We are supposed to establish bitcoin complaint handling mechanism, and protect the legitimate rights and interests of investors from the complaint handling and processing, risk compensation fund, and establishment of industry associations and other aspects.

Moreover, it is also necessary to strengthen the supervision of the platform. In view of the virtual currency supervision system, we must make a clear classification. For example, in the process of creating bitcoin regulatory system, we should implement with its own need for regulatory object. Then the content will not be feasible. Because at this stage, bitcoin is actually a test product. Standing on the technology level, we make a specific analysis. The development prospects of the virtual currency is great, while the current regulatory technology is unable to give a comprehensive regulation of virtual currency. From this point of view, this is not an optimal method that is relatively rational or meeting the cost efficiency requirements. Therefore, through the virtual currency platform, the regulation will be more convenient [15]. The reason is that bitcoin is a virtual currency, the occult is very strong. But at the same time, the platform has visible features. If the virtual currency is only the circulation between each other for the privates, then the risk is inevitable. But overall, the scale is not large, and it will not produce negative effects on social and economic development, economic order and so on. Just because of the creation of a lot of virtual currency platforms without regulation, it really expands the uncertainty of virtual currency risk [16]. Therefore, whether it is the technical level or the urgency of dealing with legal risks, based on the virtual currency platform, giving the comprehensive regulation is a real opportunity to carry out the overall supervision of the virtual currency.

China has now begun to take on-site inspection supervision measures for some of the larger bitcoin platforms. But with the continuous development of the virtual currency, the online real-time monitoring mechanism should be established. The transaction has concealment and privacy, which may lead to lower back tracking effect.

\section{Conclusion}

Bitcoin, as the most typical virtual currency, is the best carrier for the government to make the experiment. Compared to the relatively detailed supervision method in the United States, our easing policy buried a lot of "black belt" for Chinese bitcoin market. For bitcoin investors, they can truly achieve the investment purpose of arbitrage in China. The purpose of the Central Bank's 
implementation of digital currency is not to attract more people to use speculative arbitrage, but to combine the characteristics of the times and give into full play of the characteristics of digital currency portability and strong privacy, so as to help the financial market develop faster and more effectively.

At this point, the supervision measures of China and the United States are analyzed. It is found that there are many reasons leading to different regulatory ideas, including social system, Internet finance mode, and bitcoin industry. Therefore, when we study and research the regulatory system with Chinese characteristics, it is necessary to fully combine the national conditions and effectively absorb advanced ideas. Firstly, we should adhere to innovation, system, and hierarchical management principles. The supervision starts from the application platform, and after the estimation of risk, we have targeted planning. As a result, we can not only protect the legitimate interests of the trading platform, but also safeguard the legitimate rights and interests of investors, so as to to lay a good foundation for China's better development of the digital currency in the future.

\section{Acknowledgments}

Research on currency virtualization in the view of financial internet (a general item of social science prosperity project approved by university of science and technology Liaoning 2016).

\section{References}

[1]. Chen, Z. H. A. N. G. (2014). Reality of Risk of Bitcoin and China's Legal Regulation Measures. Journal of Chongqing University of Posts and Telecommunications (Social Science Edition), 5, 008.

[2]. Schmidt, R., Möhring, M., Glück, D., Haerting, R., Keller, B., \& Reichstein, C. (2016). Benefits from Using Bitcoin: Empirical Evidence from a European Country. International Journal of Service Science, Management, Engineering, and Technology (IJSSMET), 7(4), 48-62.

[3]. WEN, X., WANG, J., \& WANG, Y. (2013). Exploration and thinking of the impact of bitcoin to the financial system. Journal of Xi'an University of Posts and Telecommunications, 5, 024.

[4]. Spagnuolo, M., Maggi, F., \& Zanero, S. (2014, March). Bitiodine: Extracting intelligence from the bitcoin network. In International Conference on Financial Cryptography and Data Security (pp. 457-468). Springer, Berlin, Heidelberg.

[5]. LEVIN, R. B., O'BRIEN, A. A., \& OSTERMAN, S. A. (2014). Dread Pirate Roberts, Byzantine Generals, and Federal Regulation of Bitcoin. Journal of Taxation \& Regulation of Financial Institutions, 27(4).

[6]. Litwack, S. (2015). Bitcoin: Currency or Fool's Gold: A Comparative Analysis of the Legal Classification of Bitcoin. Temp. Int'l \& Comp. LJ, 29, 309.

[7]. Courtois, N. T., \& Bahack, L. (2014). On subversive miner strategies and block withholding attack in bitcoin digital currency. arXiv preprint arXiv:1402.1718.

[8]. Chávez, J. J. G., \& da Silva Rodrigues, C. K. (2016, August). Automatic hopping among pools and distributed applications in the Bitcoin network. In Signal Processing, Images and Artificial Vision (STSIVA), 2016 XXI Symposium on (pp. 1-7). IEEE.

[9]. Künnapas, K. (2016). From Bitcoin to Smart Contracts: Legal Revolution or Evolution from the Perspective of de lege ferenda?. In The Future of Law and eTechnologies (pp. 111-131). Springer International Publishing.

[10]. Ciaian, P., \& Rajcaniova, M. (2016). The digital agenda of virtual currencies: Can BitCoin become a global currency?. Information Systems and e-Business Management, 14(4), 883-919. 
[11]. Kim, Y. B., Lee, J., Park, N., Choo, J., Kim, J. H., \& Kim, C. H. (2017). When Bitcoin encounters information in an online forum: Using text mining to analyse user opinions and predict value fluctuation. PloS one, 12(5), e0177630.

[12]. Swartz, N. D. (2014). Bursting the Bitcoin bubble: The case to regulate digital currency as a security or commodity. Tul. J. Tech. \& Intell. Prop., 17, 319.

[13]. Brito, J., Shadab, H., \& Castillo, A. (2014). Bitcoin financial regulation: Securities, derivatives, prediction markets, and gambling. Colum. Sci. \& Tech. L. Rev., 16, 144.

[14]. Elendner, H., Trimborn, S., Ong, B., \& Lee, T. M. (2017). The Cross-Section of Crypto-Currencies as Financial Assets: Investing in Crypto-Currencies Beyond Bitcoin. In Handbook of Blockchain, Digital Finance, and Inclusion, Volume 1 (pp. 145-173).

[15]. Kowalski, P. (2015). Taxing Bitcoin Transactions Under Polish Tax Law/Opodatkowanie Obrotu Bitcoinami Na Gruncie Przepisów Polskiego Prawa Podatkowego. Comparative Economic Research, 18(3), 139-152.

[16]. Vergne, J. P., \& Swain, G. (2017). Categorical anarchy in the UK? The British media's classification of bitcoin and the limits of categorization. In From Categories to Categorization: Studies in Sociology, Organizations and Strategy at the Crossroads (pp. 185-222). Emerald Publishing Limited. 